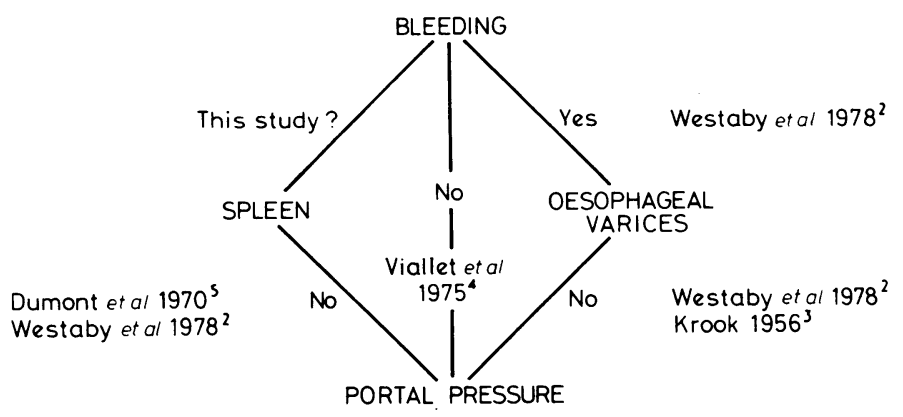

Published evidence on interrelationships between upper gastrointestinal haemorrhage and oesophageal varices, portal venous pressure and splenic enlargement.

strong evidence that the bleeding is from another site. It may therefore be appropriate to endoscope urgently only those patients in whom the spleen is palpable, while endoscopy could reasonably be postponed when the spleen is impalpable. This may be particularly appropriate in hospitals where experienced endoscopists are not on immediate recall.

In our study $27 \%$ of those who bled did so from a site other than their varices. This agrees with other British studies and also confirms that this group is smaller than in North America, where more patients bleed from gastric erosions. The relationships between the height of the portal venous pressure, the presence and size of oesophageal varices, bleeding from the varices, and the size of the spleen are not clear (figure). Oesophageal varices seen on barium swallow examination are more likely to bleed if they are large ${ }^{2}$ but, surprisingly, the portal pressure is poorly correlated with the size of varices, ${ }^{23}$ with the occurrence of bleeding, ${ }^{4}$ or with the size of the spleen. ${ }^{5}$ Our findings now link a palpable spleen with variceal bleeding. We conclude that even when varices are known to be present the absence of a palpable spleen in a patient who has an upper gastrointestinal haemorrhage and does not have gross ascites makes it unlikely that the bleeding is from varices.

PWNK is an MRC training fellow. The work was supported by the special trustees of St Thomas's Hospital and ICI Limited.

1 Schiller, K F R, and Cotton, P B, in Clinics in Gastroenterology, ed K F R Schiller, vol III, No 3, p 595. Philadelphia, W B Saunders, 1978.

2 Westaby, S, et al, Digestion, 1978, 17, 63.

${ }^{3}$ Krook, H, Acta Medica Scandinavica, 1957, Suppl, 318, 1.

4 Viallet, A, et al, Gastroenterology, 1975, 69, 1297.

5 Dumont, A E, Amarosi, E, and Stahl, W M, Annals of Surgery, 1970, $171,522$.

(Accepted 19 September 1979)

Gastrointestinal Laboratory, the Rayne Institute, St Thomas's Hospital, London SE1 7EH

J BULL, MB, MRCP, senior medical registrar

P. W N KEELING, MRCPI, MRCP, honorary senior registrar

R P H THOMPSON, DM, FRCP, consultant physician

\section{Hypercalcaemia after tamoxifen for breast cancer: a sign of tumour response?}

Hypercalcaemia occasionally occurs as an acute event in patients with advanced breast cancer after hormone treatment. ${ }^{1}$ Tamoxifen, a nonsteroidal oestrogen antagonist, is widely used for advanced breast cancer, ${ }^{2}$ and over the past two years we have treated 62 such patients with tamoxifen. We describe the course of four patients who became hypercalcaemic after starting tamoxifen.

\section{Case reports}

Case 1-A 57-year-old woman was admitted with advanced breast cancer and bone metastases. Tumour oestrogen receptor concentration was $95 \mathrm{fmol}$ $(2 \mathrm{bfg}) / \mathrm{mg}$ protein and serum calcium concentration was normal. Tamoxifen was given ( $20 \mathrm{mg}$ twice daily), and after four days she complained of nausea, vomiting, and weakness. Her serum calcium concentration was $4.0 \mathrm{mmol} / 1$ $(16.2 \mathrm{mg} / 100 \mathrm{ml})$. Tamoxifen was discontinued and she was treated with intravenous fluids and steroids. A few days later serum calcium concentration was $2.7 \mathrm{mmol} / 1(10.6 \mathrm{mg} / 100 \mathrm{ml})$. Tamoxifen was reinstituted after 10 days. Five months later serum calcium concentration was normal, she was symptom-free, and radiography showed sclerosis of previous lytic lesions.

Case 2-A 61-year-old woman was admitted with a mass in the breast and widespread osteolytic metastases. Tumour oestrogen receptor concentration was $381 \mathrm{fmol}(103.8 \mathrm{fg}) / \mathrm{mg}$ protein and serum calcium concentration was normal. Tamoxifen was given ( $10 \mathrm{mg}$ twice daily), and after four days she became confused. Serum calcium concentration was $2.9 \mathrm{mmol} / 1(11.5 \mathrm{mg} / 100$ $\mathrm{ml}$ ). Tamoxifen was discontinued and she was treated with fluids and prednisone. Three days later her condition was improved. Her serum calcium concentration was $2.5 \mathrm{mmol} / 1(10.2 \mathrm{mg} / 100 \mathrm{ml})$. Cytotoxic chemotherapy was tried and achieved temporary control.

Case 3-A 68-year-old woman with breast cancer and bone metastases was admitted because of confusion and vomiting. Serum calcium concentration was $3 \mathrm{mmol} / 1(12.3 \mathrm{mg} / 100 \mathrm{ml})$ but was normal after administration of fluids and prednisone. Tamoxifen was given ( $20 \mathrm{mg}$ twice daily), and after five days she developed weakness, and serum calcium concentration had risen to $3.0 \mathrm{mmol} / 1(12.0 \mathrm{mg} / 100 \mathrm{ml})$. Tamoxifen was stopped, and serum calcium concentration fell to $2.5 \mathrm{mmol} / 1(9.8 \mathrm{mg} / 100 \mathrm{ml})$ after fluids and steroids were administered. Cytotoxic chemotherapy was given but without response.

Case 4-A 60-year-old woman presented with stage IV breast cancer and pulmonary and bone metastases. Serum calcium concentration was normal. Tamoxifen, $20 \mathrm{mg}$ twice daily, and intermittent adriamycin and cyclophosphamide were given, and two weeks later she developed confusion and bone pain. Serum calcium concentration was $3.7 \mathrm{mmol} / 1(15.0 \mathrm{mg} / 100 \mathrm{ml})$ but became normal when she was treated with fluids, diuretics, prednisone, and oral phosphate. Her bone pains disappeared. Two months later radiography showed sclerosis of the bone metastases. Tamoxifen, adriamycin, and cyclophosphamide were continued throughout this period.

\section{Comment}

Four out of 26 patients with breast cancer and bone metastases developed acute hypercalcaemia when treated with tamoxifen (figure).

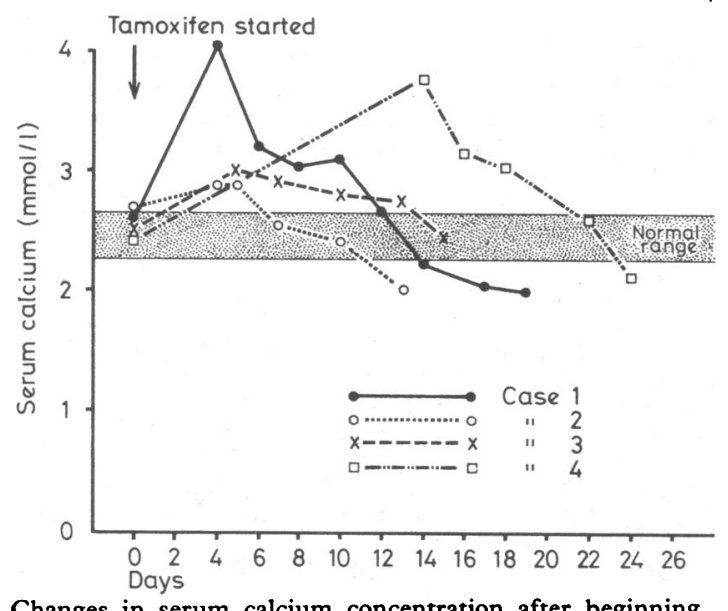

Changes in serum calcium concentration after beginning tamoxifen.

This occurred four to five days after starting tamoxifen in three patients and after two weeks in the fourth. None of the 36 patients with advanced breast cancer without bone metastases developed hypercalcaemia when treated with tamoxifen. During the study period 112 patients with advanced breast cancer were treated with cytotoxic chemotherapy and 48 underwent oophorectomy; none developed acute hypercalcaemia after treatment. We conclude that tamoxifen-induced hypercalcaemia occurs only in patients with breast cancer and bone metastases and that cytotoxic chemotherapy or oophorectomy does not cause this complication.

A recent review of 36 patients with breast cancer who became hypercalcaemic after treatment with tamoxifen showed a prevalence of hypercalcaemia of under $0 \cdot 1 \% .^{3}$ Our findings suggest that this complication may be more common. Two of our patients who became hypercalcaemic after tamoxifen had high tumour oestrogen receptor concentrations, and two showed objective tumour responses with continued treatment. Hall et $a l^{4}$ recorded tumour responses in three out of six patients who became hypercalcaemic while taking oestrogens. 
We believe that hypercalcaemia after tamoxifen may signify tumour response and be a reason for continuing with tamoxifen and treating the hypercalcaemia. This is supported by a report of tamoxifen "flare" in metastatic breast cancer and the observation that acute exacerbation of bone pain in patients with breast cancer after tamoxifen may be associated with tumour response. ${ }^{5}$ The mechanism of tamoxifeninduced tumour response needs further investigation, since acute hypercalcaemia is not seen in patients responding to chemotherapy or oophorectomy.

Requests for reprints should be sent to Professor M H N Tattersall.

${ }^{1}$ Kennedy, B J, et al, Cancer Research, 1953, 13, 455.

${ }^{2}$ Kiang, D T, and Kennedy, B J, Annals of Internal Medicine, 1977, 87, 687.

3 Patterson, J S, Furr, B J A, and Battersby, L A, Annals of Internal Medicine, 1978, 89, 1013

${ }^{4}$ Hall, T C, Dederick, M M, and Nevinny, H B, Cancer Chemotherapy Reports, 1963, 30, 21.

5 Plotkin, D, et al, Fournal of the American Medical Association, 1978, 240, 2644

(Accepted 4 September 1979)

Sydney Cancer Therapy Branch, Ludwig Institute for Cancer Research, University of Sydney and Royal Prince Alfred Hospital, Sydney, NSW 2006

ANTONIO H VILLALON, MD, clinical research fellow (scholarship from Andres Soriano Cancer Research Foundation, Manila, Philippines)

MARTIN H N TATTERSALL, MD, FRACP, professor of cancer medicine, and director

RICHARD M FOX, PHD, FRACP, associate professor of cancer medicine

ROBERT L WOODS, MB, MRCP, associate physician in medical oncology

\section{Hydrallazine-induced SLE-like syndrome presenting as a leg ulcer}

The use of hydrallazine for systemic hypertension may be complicated by a syndrome resembling systemic lupus erythematosus (SLE) in $10-15^{\circ} \%$ of patients after cumulative doses exceeding $100 \mathrm{~g} .{ }^{1}{ }^{\mathrm{W}} \mathrm{We}$ describe a patient who presented with a painful leg ulcer.

\section{Case report}

A 50-year-old man admitted in January 1979 had a nine-week history of a painful ulcer above the right heel, which had steadily enlarged and prevented walking. He had a nine-month history of symptoms suggestive of Raynaud's phenomenon, joint pains for three months, malaise for six weeks, and an itchy rash over the left shin and forearm for one week. Malignant hypertension was diagnosed in 1970 (blood pressure $250 / 130 \mathrm{~mm} \mathrm{Hg}$ ) and treatment instituted with debrisoquine. In 1976 he was admitted with a blood pressure of $270 / 180 \mathrm{~mm} \mathrm{Hg}$ and hydrallazine treatment was begun (150 mg daily). There was no diabetes mellitus, vascular insufficiency, or trauma. He smoked 15 cigarettes daily.

He was drowsy, with mild tachycardia $(100 / \mathrm{min})$ and low-grade fever $(37.5 \mathrm{C})$. Blood pressure was $220 / 150 \mathrm{~mm} \mathrm{Hg}$ (supine) and $190 / 135 \mathrm{~mm} \mathrm{Hg}$ (erect). The ulcer $(3-5 \mathrm{~cm}$ diameter), directly over the right tendo Achillis, was superficial, but the edge was discoloured and the base encrusted with old blood. There was no arterial or venous insufficiency or regional lymphadenopathy. There was severe wasting of the right quadriceps muscle, equinus deformity of the right ankle, and a diffuse purpuric rash over the left shin and forearm

Haemoglobin concentration was $12.8 \mathrm{~g} / \mathrm{dl}$ but white cell and platelet counts were normal. Plasma viscosity was raised $(1.92 \mathrm{mPa} \mathrm{s} ; 1.92 \mathrm{cp})$, serum iron concentration $6.9 \mu \mathrm{mol} / \mathrm{l}(38.5 \mu \mathrm{g} / 100 \mathrm{ml})$, total iron-binding capacity $47 \mu \mathrm{mol} / 1(262.5 \mu \mathrm{g} / 100 \mathrm{ml})$, blood urea concentration $8.1 \mathrm{mmol} / 1$ $(48.6 \mathrm{mg} / 100 \mathrm{ml})$, and creatinine clearance $52 \mathrm{ml} / \mathrm{min}$. Titre for antinuclear factor (ANF) was $1 / 320$ and DNA antibody binding $21 \%$. IgM concentration was $9.0 \mathrm{~g} \mathrm{l}$, but complement values were normal. Random blood glucose estimations, chest and ankle radiographs, and Wassermann and latex fixation tests showed no abnormalities. The patient was a slow acetylator as assessed by sulphadimidine clearance. A biopsy specimen of the ulcer disclosed fibrosing granulation tissue.

All these features suggested that an SLE-like syndrome may have caused this patient's indolent ulcer. Since total hydrallazine exposure may have been relevant the drug was replaced by atenolol and bendrofluazide. With bed rest, raising the leg, and cleaning the ulcer locally his condition rapidly improved. The rash disappeared five days after stopping hydrallazine, and by one week the ulcer was healing; this was accelerated by applying split-skin grafts. At discharge plasma viscosity was $1.7 \mathrm{mPa} \mathrm{s}(1.7 \mathrm{cp})$. After four months he was in good health and had returned to work. The ulcer had healed, and after physiotherapy his ankle and thigh had returned to normal. Blood pressure was controlled at $140 / 90 \mathrm{~mm} \mathrm{Hg}$. Plasma viscosity, ANF titres, and DNA antibody binding were unchanged.

\section{Comment}

Dubois $^{2}$ reviewed 520 cases of idiopathic SLE and found a 5\% incidence of leg ulceration but this complication has not been reported in hydrallazine-induced SLE. About $10^{\circ} \%$ of cases of SLE may be caused by drugs, notably hydrallazine. Patients may develop a positive ANF titre with hydrallazine without having SLE-like symptoms. ${ }^{3}$ This phenomenon was also shown for prazosin. ${ }^{4}$ Druginduced SLE differs from idiopathic SLE in affecting older people, relatively more men, and the lung and kidney less often; DNA antibody binding is under $30 \% .^{3}$ Some $96 \%$ of patients with druginduced SLE are slow acetylators. ${ }^{35}$ Although first described in patients taking large daily doses of hydrallazine $(400 \mathrm{mg}){ }^{3}$ the syndrome may occur with lower doses $(150 \mathrm{mg})^{5}$; the cumulative dosage appears to be more important. Symptoms usually disappear within four months of stopping hydrallazine, but ANF titres and DNA antibody binding may take up to six years to return to normal. ${ }^{5}$

The relation between toxic symptoms and hypertensive control is not clear. Perry ${ }^{3}$ suggested that toxicity was associated with control of blood pressure and that suddenly stopping treatment led to rebound hypertension. In our case toxicity was associated with failure of hypertensive control. We suggest that acetylator states of all patients taking long-term hydrallazine should be determined to identify those at risk from drug-induced SLE. Once hypertension is controlled the daily dose should be reduced to the minimum needed to maintain normal blood pressure.

${ }^{1}$ Alarcon-Segovia, D, Clinics in Rheumatic Diseases, 1975, 1, 573.

${ }^{2}$ Dubois, E L, Lupus Erythematosus. Los Angeles, University of Southern California Press, 1974.

${ }^{3}$ Perry, H M, American fournal of Medicine, 1973, 54, 58.

${ }^{4}$ Marshall, A J, McGraw, M E, and Barritt, D W, British Medical Fournal, $1979,1,165$.

${ }^{5}$ Strandberg, I, et al, Acta Medica Scandinavica, 1976, 200, 367.

(Accepted 7 September 1979)

Department of Surgery, Bristol Royal Infirmary, Bristol BS2 8HW

$M$ W KISSIN, MB, BCHIR, senior house officer

R C N WILLIAMSON, MCHIR, FRCS, professor

\section{Gallium-67 scanning in pyrexia of unknown origin}

Pyrexia of unknown origin (PUO) is a common problem in clinical medicine, occurring either as a presenting feature or as a postoperative complication. We have assessed the efficacy of ${ }^{67} \mathrm{Ga}$ scanning as a non-invasive investigation of PUO.

\section{Methods and results}

We reviewed retrospectively 67 consecutive scans performed on 61 patients with PUO referred to our department in one year. The PUO had been present for several days to several weeks, and routine investigations including blood, sputum, and urine cultures, chest radiography, and intravenous urography, had not determined its origin. Imaging was performed 48 and 72 hours after intravenous injection of $75-100 \mathrm{MBq}(2-2.7 \mathrm{mCi})$ gallium citrate ("i $\mathrm{Ga}$; Radiochemical Centre). Patients were not prepared before injection, but unless contraindicated Dorbanex tablets (danthronpoloxamer) were given 12-hourly for 72 hours afterwards. Imaging was performed with an Ohio Nuclear 84 double-headed rectilinear scanner with 5:1 ratio minification using a high-energy collimator and an analyser setting that accepted the 185 and $296 \mathrm{keV}$ peaks of ${ }^{67} \mathrm{Ga}$. Patients were imaged from neck to thigh. When indicated, a liver-spleen scan with ${ }^{99} \mathrm{~m}$ Tc-sulphur colloid was performed after the ${ }^{67} \mathrm{Ga}$ scan at 72 hours, the patient being kept in the same position to permit superimposition of the scans. Gallium-67 scans were regarded as normal when uptake was seen only in sites of physiological accumulation, and abnormal when uptake was seen at other sites, provided relative uptake increased between 48 and 72 hours.

Of the $67^{6 i \mathrm{Ga}}$ scans, 50 were abnormal. Most sites of abnormal uptake were in the abdomen (table), miscellaneous sites consisting mainly of 